\title{
Are children more vulnerable to mesothelioma than adults? A comparison of mesothelioma risk among children and adults exposed non-occupationally to blue asbestos at Wittenoom
}

\author{
Alison Reid, ${ }^{1}$ Peter Franklin, ${ }^{2}$ Geoffrey Berry, ${ }^{3}$ Susan Peters, ${ }^{2,4,5}$ Nita Sodhi-Berry, ${ }^{2,3}$ \\ Fraser Brims, ${ }^{6,7}$ Arthur William Musk, ${ }^{2}$ Nicholas H de Klerk ${ }^{2,8}$
}

${ }^{1}$ School of Public Health, Curtin University, Bentley, Western Australia, Australia

${ }^{2}$ School of Public and Global Health, University of Western Australia, Perth, Western Australia, Australia

${ }^{3}$ Sydney School of Public Health, University of Sydney, Sydney, New South Wales, Australia ${ }^{4}$ Institute for Risk Assessment Sciences, Utrecht University, Utrecht, The Netherlands ${ }^{5}$ Department of Neurology, University Medical Center Utrecht, Utrecht, The Netherlands

${ }^{6}$ Faculty of Health Sciences, Curtin Medical School, Curtin University, Bentley, Western Australia, Australia ${ }^{7}$ Department of Respiratory Medicine, Sir Charles Gairdner Hospital, Perth, Western Australia, Australia

${ }^{8}$ Telethon Kids Institute, University of Western Australia, Crawley, Western Australia, Australia

\section{Correspondence to} Dr Alison Reid, School of Public Health, Curtin University, Bentley, WA 6102, Australia; alison.reid@curtin.edu.au

Received 5 March 2018 Revised 26 June 2018 Accepted 5 August 2018

Published Online First 29 August 2018

Check for updates

(C) Author(s) (or their employer(s)) 2018. No commercial re-use. See rights and permissions. Published by BMJ.

To cite: Reid A,

Franklin P, Berry G, et al.

Occup Environ Med

2018:75:898-903.

\section{ABSTRACT}

Objectives The presence of asbestos in public buildings is a legacy of past asbestos use in many developed countries. Of particular concern is the amount and current condition in schools and the vulnerability of children to mesothelioma. Our aim was to compare the risk of mesothelioma between those exposed to blue asbestos as children and as adults at Wittenoom. Methods Public sources were used to establish the Wittenoom residents' cohort. Mesothelioma incidence rates per 100000 person-years at risk were derived for those first exposed to asbestos at Wittenoom as children ( $<15$ years) or adults separately. Proportional hazards survival models examined the slope of the exposureresponse relationship between asbestos exposure and incidence of mesothelioma in different sex and age groups.

Results The mesothelioma rate was lower among those first exposed as children (76.8 per 100000 ) than those first exposed as adults (121.3 per 100 000). Adjusting for cumulative exposure to asbestos and sex, those exposed as adults had a greater risk of mesothelioma (adjusted HR 2.5, 95\% Cl 1.7 to 3.7). The slope of the exposure-response relationship did not differ between those exposed as children and those exposed as adults. Conclusion We found no greater susceptibility to mesothelioma among those first exposed to asbestos as children than those first exposed as adults. However, given the long latency of mesothelioma, and the greater years of life yet to be lived by the Wittenoom children, it is likely that there will be more cases of mesothelioma in the future among those first exposed as children.

\section{INTRODUCTION}

Malignant mesothelioma is a cancer that arises from the mesothelial lining of the chest and abdominal cavities and is almost exclusively associated with exposure to asbestos. Mesothelioma responds poorly to any form of clinical treatment and is universally fatal with most deaths occurring between 6 and 12 months after diagnosis. ${ }^{1}$ Mesothelioma is characterised by a long latency period (that period between first exposure to asbestos and subsequent diagnosis or death) between 20 and 50 years. $^{23}$

The presence of asbestos in public buildings is a legacy of past asbestos use in many developed

\section{Key messages}

What is already known about this subject?

- The UK's Committee on Carcinogenicity recently estimated that the lifetime risk of a child first exposed to asbestos at age 5 compared with an adult exposed at age 25 was about 3.5 times greater, and five times greater than an adult first exposed at age 30 .

What are the new findings?

- This study finds that those first exposed to asbestos as children do not appear to have an increased susceptibility to mesothelioma, which is contrary to exposure to most environmental pollutants.

How might this impact on policy or clinical practice in the foreseeable future?

- Those first exposed to asbestos as children appear to have no greater intrinsic susceptibility to injury from asbestos exposure than those first exposed as adults, but given the long latency of mesothelioma and the differences in life expectancy, their lifetime risk of developing mesothelioma is likely to be greater.

countries. ${ }^{4}$ Of particular concern is the amount of asbestos-containing materials and their current condition in schools, with the resulting risk of mesothelioma to children and staff. ${ }^{5}$ A recent review of the evidence examining the vulnerability to asbestos of children compared with adults, conducted for the UK Department for Education, concluded that 'exposure of children to asbestos is likely to render them more vulnerable to developing mesothelioma than exposure of adults to an equivalent asbestos dose,' largely because of the effects of latency. ${ }^{6}$

The vulnerability of children to asbestos exposure and risk of mesothelioma has been examined previously among the 2500 children who lived in the town of Wittenoom in Western Australia (WA) between 1943 and $1966 .^{7}$ Tailings from the mine were distributed around the town to pave roads and footpaths, school playgrounds, the race course and in the backyards of houses. Earlier work with follow-up to the year 2000 showed lower rates 
of mesothelioma among those first exposed to blue asbestos at Wittenoom as children (aged $<15$ years); 47 per 100000 personyears compared with those first exposed as adults (aged $\geq 15$ years); 112 per 100000 person-years. ${ }^{7}$ Subsequent follow-up of these Wittenoom children to 2009 showed a mesothelioma rate of 44.6 per 100000 (28.1 in women, 60.4 in men). ${ }^{8}$ The aim of this current study was to compare the risk of malignant mesothelioma among those first exposed to blue asbestos non-occupationally at Wittenoom as children with those first exposed as adults, with extended follow-up to December 2014.

\section{METHODS}

Blue asbestos (crocidolite) was mined and milled at Wittenoom in the Pilbara region of WA between 1938 and 1966. Prior to 1943, smaller works had been operated by hand cobbing. In 1943, the operations were taken over by the Australian Blue Asbestos (ABA), increased in size and mechanised. Approximately 7000 workers were employed by ABA. A further 5000 residents lived and worked in the town that was established to support the mining operation but did not work for ABA. The townsite was located initially $1 \mathrm{~km}$ away from the mill, but was moved to $12 \mathrm{~km}$ away in 1947 to accommodate the increasing population. ${ }^{9-11}$

\section{Wittenoom residents' cohort}

The methods used to establish the residents' cohort have been fully described previously ${ }^{10-12}$ : from a range of public sources (eg, state primary school records, hospital admission and outpatient records, state electoral roll for the Pilbara region) and from questionnaires mailed to members of the Wittenoom workers' cohort, established earlier from ABA employment records, ${ }^{9}$ were used to identify the former residents of the township. In total, 18553 records identified 5097 individuals recorded as having lived in Wittenoom between 1943 and 1993 and who had not worked for the asbestos company. A questionnaire was sent to those residents who could be traced to an address in Australia in 1993, seeking information on demographics, date, length and place of residence at Wittenoom, occupation at Wittenoom, whether they lived with or washed the clothes of an asbestos worker, smoking history and medical history. ${ }^{10-12}$

A cohort of 4890 residents was established..$^{10}$ Continued refinement of the cohort (eg, deleting duplicates, finding out new information from participants, and so on) over time accounts for differences in numbers of subjects from earlier reports. ${ }^{70-12}$ As of 2017, the cohort consisted of 4704 former residents of whom 2439 (52\%) were first exposed to asbestos at Wittenoom as children. Only children aged $<15$ years were included in the children's cohort in order to avoid any potential occupational exposure, as the legal age permitted for work in the mine and mill was 15 years.

\section{Exposure assessment}

Dates of residence at Wittenoom were provided by responses to the questionnaire. Where a resident remained untraced, was dead or did not return a questionnaire and if they were related to an ABA worker, their dates and place of residence at Wittenoom were assumed to be the same as those of the worker. Where they were unrelated to a worker, dates of residence were assumed to be the same as that of other family members, with the provision that at least one family member had documented exposure. In all other cases dates of residence were taken from the sources used to establish the cohort. ${ }^{11} 12$
Several surveys of airborne dustiness were conducted throughout the township of Wittenoom using personal and fixed positional monitors between 1973 and $1992 .{ }^{10}$ On the basis of these measurements, residents were assigned 1.0 fibre/ $\mathrm{mL}(\mathrm{f} / \mathrm{mL})$ of air between 1943 and 1957 when an original mill was in operation, $0.5 \mathrm{f} / \mathrm{mL}$ between 1958 when a new mill was in operation and 1966 when both the mine and mill were closed. Exposures of $0.5 \mathrm{f} / \mathrm{mL}$ in 1966 down to $0.010 \mathrm{f} / \mathrm{mL}$ in 1992 were assigned after interpolation between the dust surveys that used personal monitors. The intensity of exposure was combined with the duration of residence to estimate cumulative exposure. Cumulative exposure estimates were further adjusted by a factor of 4.2 to account for a 24 -hour day/7 days a week exposure. $^{10-12}$

\section{Follow-up and case ascertainment}

The cohort is periodically linked to the Western Australian and national death registries and cohort participants are sent infrequent questionnaires (the last in 2010) and/or participate in a cancer surveillance programme. ${ }^{13}{ }^{14}$ In addition, to ascertain if they had had a change in surname, all women were searched for in the Marriage Register of WA. Death certificates of any spouse, and birth, marriage and death certificates of any children were sought to obtain the mother's maiden name..$^{15}$ Mesothelioma is mandatorily reported in Australia (as are all cancers except non-melanotic skin cancer) and cases were ascertained from the National Cancer Statistics Clearing House, the Australian Mesothelioma Register and the Western Australian Mesothelioma Register.

Approximately $20 \%$ of the cohort has been lost to follow-up, therefore two methods were used to derive person-years at risk, based on different censoring dates. The first method assumed that all persons not known to have developed mesothelioma and not known to have died were still alive at the end of the follow-up period of 31 December 2014. The second method censored persons at their date last known to be alive if they were not known to have mesothelioma or not known to have died. The first method tends to overestimate person-years at risk thereby providing a minimum estimate of the mesothelioma rate while the second method underestimates the person-years at risk so providing a maximum estimate of the mesothelioma rate. The true rate will lie somewhere between the two. The minimum rate estimate is shown in the tables that follow.

\section{Statistical analysis}

Mesothelioma incidence rates per 100000 person-years at risk were derived for various categories of asbestos exposure and for those first exposed to asbestos at Wittenoom as children (aged $<15$ years) or adults (aged $\geq 15$ years) separately. For each exposure category, the number of cases was divided by the number of person-years in the same category and multiplied by 100000 . The rates were calculated with follow-up from 20 years after first exposure until death, mesothelioma incidence or age 85 (whichever was earliest).

Proportional hazards survival models with a Weibull distribution for the hazards examined the slope of the exposure-response relationship between asbestos exposure and incidence of mesothelioma in the different sex and age groups. Because of the way Weibull regression models the underlying time variable, these analyses included follow-up from the date of first exposure. All analyses were performed using Stata V.14. ${ }^{16}$ 
Table 1 Asbestos exposure characteristics of former residents of Wittenoom by age of first residence

\begin{tabular}{|c|c|c|c|}
\hline & $\begin{array}{l}\text { First exposed } \\
\text { aged }<15 \text { years }\end{array}$ & $\begin{array}{l}\text { First exposed } \\
\text { aged } \geq 15 \text { years }\end{array}$ & Total \\
\hline$n$ & 2439 & 2265 & 4704 \\
\hline Female & $1176(48.2)$ & $1343(59.3)$ & $2519^{*}$ \\
\hline \multicolumn{4}{|l|}{ Age at Wittenoom (years) } \\
\hline 0 to $<5$ & $1553(63.7)$ & & $1553(33)$ \\
\hline 5 to $<10$ & $637(26.1)$ & & $637(13.5)$ \\
\hline 10 to $<15$ & $249(10.2)$ & & $249(5.3)$ \\
\hline 15 to $<30$ & & $1204(53.2)$ & $1204(25.6)$ \\
\hline $30+$ & & $891(39.3)$ & $891(18.9)$ \\
\hline Missing & & $170(7.5)$ & $170(3.6)$ \\
\hline \multicolumn{4}{|l|}{ Year of arrival } \\
\hline$\leq 1958$ & $866(35.5)$ & $627(27.7)$ & $1493(31.7)^{*}$ \\
\hline 1959-1966 & $1038(42.5)$ & $722(31.9)$ & $1760(37.4)$ \\
\hline $1967+$ & $535(21.9)$ & $839(37.0)$ & $1374(29.2)$ \\
\hline Missing & & $77(3.4)$ & $77(1.6)$ \\
\hline Lived with ABA worker & $1760(72)$ & $679(28)$ & $2670(57)^{*}$ \\
\hline \multicolumn{4}{|c|}{ Duration of residence (years) } \\
\hline$<2$ & $1347(55.2)$ & $1248(55.1)$ & $2595(55.2)$ \\
\hline 2 to $<5$ & $685(28.1)$ & $498(21.9)$ & $1183(25.2)$ \\
\hline 5 to $<10$ & $239(9.8)$ & $232(10.2)$ & $471(10.0)$ \\
\hline $10+$ & $156(6.4)$ & $164(7.2)$ & $320(6.8)$ \\
\hline Missing & $12(0.49)$ & $123(5.4)$ & $135(2.9)$ \\
\hline \multicolumn{4}{|c|}{ Time from first exposure to exit (years) } \\
\hline 0-19 & $66(2.7)$ & $172(7.6)$ & $238(5.1)^{*}$ \\
\hline $20-29$ & $35(1.4)$ & $204(9.0)$ & $240(5.1)$ \\
\hline $30-39$ & $154(6.3)$ & $384(16.9)$ & $538(11.4)$ \\
\hline $40-49$ & $708(29.0)$ & $732(32.3)$ & $1440(30.6)$ \\
\hline $50-59$ & $1122(46.0)$ & $571(25.2)$ & $1693(36.0)$ \\
\hline $60+$ & $354(14.5)$ & $124(5.5)$ & $478(10.2)$ \\
\hline Missing & 0 & $77(3.4)$ & $77(1.64)$ \\
\hline \multicolumn{4}{|c|}{ Cumulative exposure (f/mL-years) } \\
\hline 0 to $<5$ & $1499(64.5)$ & $1496(66.0)$ & $2995(63.7)^{*}$ \\
\hline 5 to $<10$ & $463(19.0)$ & $270(11.9)$ & $733(15.6)$ \\
\hline $10+$ & $421(17.3)$ & $295(13.0)$ & $716(15.2)$ \\
\hline Missing & $56(2.3)$ & $204(9.01)$ & $260(5.5)$ \\
\hline Mesotheliomas, n (\%) & $59(2.4)$ & $60(2.7)$ & $119(2.5)$ \\
\hline Dead (all causes), n (\%) & $301(12.3)$ & $953(42.1)$ & $1254(26.7)^{*}$ \\
\hline
\end{tabular}

${ }^{*} \mathrm{P}<0.001$ ( $\mathrm{X}^{2}$ test for group).

$A B A$, Australian Blue Asbestos.

\section{RESULTS}

Of the 4704 former residents of Wittenoom, 2439 (52\%) arrived there as children (table 1). Year of arrival, cumulative exposure and time since first exposure (until end of follow-up) differed significantly between those first exposed as children and those first exposed as adults. Children were more likely to have been residents at Wittenoom prior to 1958 when the original 'dirty' mill was working. Children had a greater estimated cumulative exposure compared with adults, geometric mean $3.02 \mathrm{f} / \mathrm{mL} \cdot$ years (IQR 1.40-7.70) and $2.05 \mathrm{f} / \mathrm{mL} \cdot$ years (IQR 0.90-5.75), respectively. Time since first exposure was longer among children (mean 51.1 years, SD 10.3) than adults (mean 42.4 years, SD 13.6). Twelve per cent of the children compared with $42 \%$ of the adults had died by the end of follow-up although the number of mesotheliomas was similar in both groups.

The mesothelioma rate per 100000 person-years was nearly $60 \%$ higher among those first exposed as adults compared with those first exposed as children (table 2). Women in both groups had lower rates than men, although 95\% CIs overlapped. Rates were highest in both groups for those with longer durations of exposure and higher cumulative exposure. The mesothelioma rate was lower among children than adults by categories of time since first exposure for all periods, although CIs overlapped (table 3). However, numbers are few in the higher time categories and CIs wide. We repeated this analysis to look at those who had only ever been exposed to asbestos at Wittenoom as children, so children aged $\leq 5$ years on first arrival at Wittenoom and with a duration of residence $<10$ years $(n=1429)$. The pattern of mesothelioma rates per 100000 is similar to that of those first exposed aged $<15$ years (table 3 ).

After adjusting for cumulative exposure and sex, those first exposed to asbestos as adults had a greater risk of mesothelioma than those first exposed as children (table 4) with an HR of 2.51. Overall, the mesothelioma risk increased by 3.1 per 10 -fold increase in $\mathrm{f} / \mathrm{mL}$-years and there was no significant difference in this effect between men and women ( $p$ for interaction $=0.22)$ or between the adult-and-child-exposed groups $(p$ for interaction $=0.58$ ). Separate analyses, stratified by the two age at exposure groups, indicated that the difference between the two groups was the same over the whole follow-up period and provided no better fit.

Further, we repeated this model on those who had only ever been exposed to asbestos at Wittenoom as children, so children aged $\leq 5$ years on first arrival at Wittenoom and with a duration of residence $<10$ years, comparing them with those who were aged between 20 and 25 years at first exposure and with a duration of residence $<10$ years. The HR (for the older group) was 4.51 (95\% CI 2.32 to 8.75 ), adjusting for $\log 10$ cumulative exposure $(4.92,95 \% \mathrm{CI} 2.35$ to 10.3$)$ and male sex (2.98, $95 \%$ CI 1.56 to 5.69 ), based on 45 mesotheliomas and 1894 observations.

Marked differences were not observed when all analyses and models were repeated after deriving person-years at risk based on censoring those lost to follow-up at their date last known to be alive: as expected all the estimated rates were higher (103 and 173 per 100000 in the two age groups) but the adjusted HR for the adult-exposed group was similar $(2.57,95 \%$ CI 1.73 to 3.81).

\section{DISCUSSION}

Earlier work examining former residents of Wittenoom first exposed to asbestos as children followed up until 2002 showed a rate of mesothelioma that was $42 \%$ of those first exposed as an adult (47 vs 112 per 100000 , respectively), and an increased risk of mesothelioma among those first exposed to asbestos as adults (HR 3.88, 95\% CI 2.22 to 6.78). ${ }^{7}$ With 12 additional years of follow-up and 65 more mesothelioma cases, this current study finds that the rate of mesothelioma by time since first exposure, per 100000 , is still significantly different between the age groups, although by not quite so much. The rate among those first exposed to asbestos as children (76.8 per 100000$)$ has increased from that reported earlier (47 per $100000) .^{7}$ The rate among those first exposed as adults has also increased (but by not quite so much) with the longer follow-up from 112 per 100000 to 121.3 per 100000 . However, the risk of mesothelioma remains significantly higher among those first exposed as adults (HR 2.51, 95\% CI 1.69 to 3.72). There was no difference in the exposure-response slope between those first exposed as children and those first exposed as adults. In contrast to the previous study there was also no difference in the 
Table 2 Number of cases of mesothelioma and the rate per 100000 person-years more than 20 years after first exposure up to age 85 , by characteristics of asbestos exposure among former Wittenoom residents by age of first residence

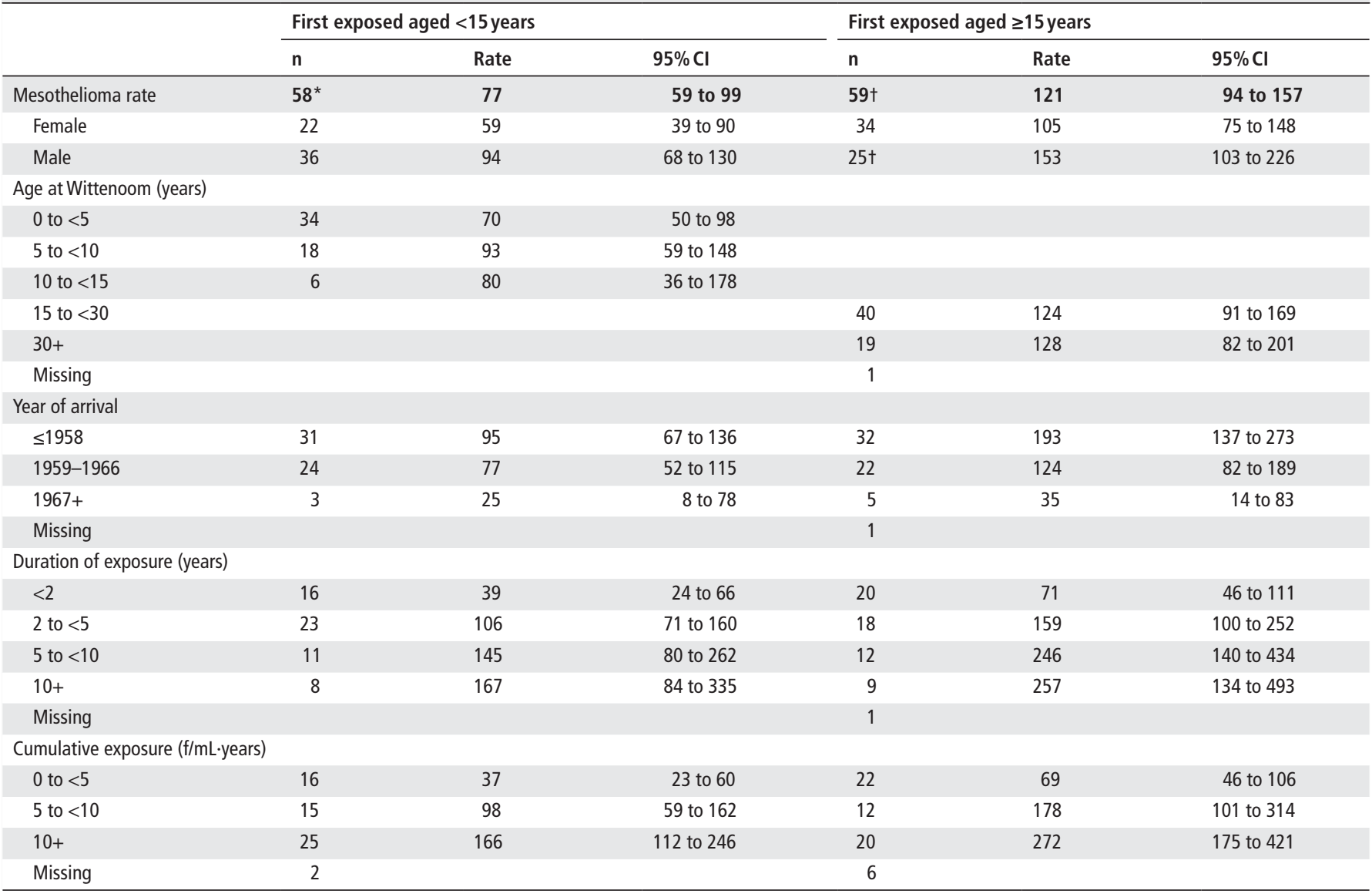

${ }^{*}$ One case in those exposed aged $<15$ years excluded because it occurred $<20$ years after first exposure.

tOne case in those exposed aged $>15$ years excluded because there was no exposure information derived for this participant.

The overall mesothelioma rate for Children and adults is shown in bold.

exposure-response slope between men and women. At the end of follow-up (2014), 58\% of adults were still alive compared with $88 \%$ of children, but in both groups there had been a similar number of incident cases of mesothelioma (59 and 60, respectively). If this cohort is to be followed up indefinitely, it appears likely that there will be more deaths from mesothelioma in those first exposed as children than in those first exposed as adults, given the long latency of this disease. Even if the rate remains lower for those first exposed aged $<15$ years, more deaths from mesothelioma will probably occur in this group because they will eventually accrue substantially more person-years at risk than those who were first exposed as adults.
Few studies have the capacity to examine the risk of mesothelioma among persons exposed to asbestos as children. Work from New Caledonia reported the highest risk of pleural mesothelioma among those who were first exposed to asbestos (whitewash made of pure tremolite) at birth. Compared with those first exposed aged $\geq 16$ years ( 0 case), the OR for those first exposed at birth and for those first exposed at age $<16$ years was 52.8 , $95 \%$ CI 6.53 to 427 , based on 13 cases, and 20.0, 95\% CI 1.09 to 368 , based on a single case, respectively. ${ }^{17}$ Other studies have not examined risks associated with asbestos exposure in children specifically, but have compared the risk or rate of mesothelioma in workers first exposed aged less than 25,30 or 35 years with

Table 3 Rate of mesothelioma, per 100000 person-years (up to age 85) among former Wittenoom residents, by categories of time since first exposure and age at first residence

\begin{tabular}{|c|c|c|c|c|c|c|c|c|c|}
\hline \multirow{2}{*}{$\begin{array}{l}\text { Time since first } \\
\text { exposure (years) }\end{array}$} & \multicolumn{3}{|c|}{ First exposed aged $\leq 5$ years* } & \multicolumn{3}{|c|}{ First exposed aged $<15$ years } & \multicolumn{3}{|c|}{ First exposed aged $>15$ years } \\
\hline & $\mathrm{n}$ & Rate & $95 \% \mathrm{Cl}$ & $\mathbf{n}$ & Rate & $95 \% \mathrm{Cl}$ & $\mathrm{n}$ & Rate & $95 \% \mathrm{Cl}$ \\
\hline $20-29$ & 0 & 0 & & 3 & 13 & 4 to 39 & 7 & 36 & 17 to 76 \\
\hline $30-39$ & 10 & 75 & 40 to 139 & 15 & 66 & 40 to 109 & 19 & 117 & 75 to 184 \\
\hline $40-49$ & 9 & 78 & 41 to 150 & 20 & 104 & 67 to 162 & 25 & 247 & 167 to 366 \\
\hline $50-59$ & 8 & 146 & 73 to 292 & 16 & 181 & 112 to 296 & 7 & 237 & 113 to 498 \\
\hline $60-69$ & 1 & 157 & 22 to 1117 & 4 & 358 & 134 to 953 & 1 & 578 & 81 to 4105 \\
\hline Unknown & & & & & & & 1 & & \\
\hline
\end{tabular}

${ }^{*}$ With $<10$ years of duration of residence at Wittenoom. 


\begin{tabular}{|c|c|c|}
\hline Variables & HR $(95 \% \mathrm{Cl})$ & $P$ values \\
\hline Cumulative exposure, per log $10 \mathrm{f} / \mathrm{mL}$-years & 3.10 (2.11 to 4.53$)$ & $<0.001$ \\
\hline Women & 1.00 & \\
\hline Men & 1.95 (1.33 to 2.88 ) & 0.001 \\
\hline Wittenoom child & 1.00 & \\
\hline Wittenoom adult & 2.51 (1.69 to 3.72$)$ & $<0.001$ \\
\hline
\end{tabular}

those first exposed at an older age. Overall, the conclusions are mixed. Higher risks were reported in four studies of workers first exposed to asbestos aged $<15,<25$ or $<30$ years compared with workers first exposed aged $>30$ or 35 years. ${ }^{18-21}$ In three of these studies, ${ }^{181921}$ CIs were wide and overlapped (indicating that the differences between groups were not statistically significant). Among men exposed for a duration of 30 years or longer, compared with those first exposed at age 10 years, the OR for a man first exposed at age 15 years was 1.1 (95\% CI 0.3 to 3.8 ). The OR for a man first exposed at age 30 years was 0.2 (95\% CI 0.0 to 0.7 ), suggesting a possible exposure-response relationship with age at first exposure, although the relationship was less pronounced for those with less than 30 years' duration of exposure. ${ }^{20}$ Similarly, Rake et al reported a mesothelioma risk that was increased among both women and men (OR 2.0, 95\% CI 1.3 to 3.2 ) who had lived with a high-risk worker before the age of 30 , although it is not clear how many of those 50 cases were aged less than 15 years at first exposure. ${ }^{21}$ Together, these studies suggest a decreased risk of mesothelioma with increasing age at first exposure which contradicts the results of the current study. In contrast, Chen et al reported lower SMRs for workers exposed to asbestos before the age of 20 (SMR 5556, 95\% CI 2873 to 9723 ) compared with those exposed aged $\geq 20$ years (SMR 7494, 95\% CI 2428 to 17462 ), ${ }^{22}$ although again, CIs were wide and overlapped indicating that the differences between the groups were not statistically significant. Other work has estimated that the lifetime risk of mesothelioma is 3.5 times greater for a child first exposed at age 5 compared with an adult at age 25 and five times greater than that of an adult first exposed at age 30. This assumes the same rates for those first exposed as adults and children, but applies those rates to a longer survival period expected in those first exposed at age 5.6 A review of the literature comparing mesothelioma risk between those exposed as adults or children concluded that the effect of asbestos exposure occurring during childhood remains unclear and warrants further research. ${ }^{23}$

An examination of the pathophysiological mechanisms that occur following asbestos exposure and any differences that might exist between children and adults may help explain why we found that those first exposed to asbestos as children have lower rates of mesothelioma than those first exposed as adults. The pattern of fibre deposition and clearance may differ between children and adults. Children have faster and shallower breathing rates than adults which may influence where the asbestos fibres are deposited. Particle deposition models for children suggest they are more likely to deposit in the extrathoracic and trachea-bronchial regions than adults, and have lower deposition in the lower airways. ${ }^{624}$ Clearance mechanisms may also be more efficient in children, than adults, because there is less distance for the fibres to travel to be removed and mucociliary clearance from conducting airways is more efficient than cellular clearance from the lung periphery. A clearance rate of between $10 \%$ and $15 \%$ per annum has been estimated among highly occupationally exposed cohorts, ${ }^{25}$ but the rate for children is unknown. In addition, inhaled fibres resulting from environmental exposure tend to be shorter and finer and so are likely to be removed more rapidly from the lungs than longer fibres. ${ }^{26}$

Uncertainty remains about the level of risk of developing mesothelioma following low-level environmental exposure, although there is no known threshold below which exposure to asbestos is safe. ${ }^{27}$ We currently lack information on the deterioration of in situ asbestos or its importance to ambient exposures. ${ }^{28}$ In particular, does time spent in buildings containing asbestos make a material contribution to that exposure for some people? Further, does such exposure, for example from schools, make a greater contribution if the risk is higher for exposure starting in childhood? Seventy-five per cent of schools in England are estimated to contain some form of asbestos-containing products (eg, asbestos insulating board) and amphibole (amosite) and serpentine (chrysotile) asbestos have been used in their construction. ${ }^{62930}$ A common source of asbestos exposure in those schools is from poorly maintained, disturbed or damaged asbestos insulation or asbestos cement-containing products that released fibres into the air. The prevailing wisdom suggests that such exposure does make a greater contribution to risk, based on latency alone. However, this wisdom was not obtained from direct observation, but from extrapolation of risks seen at high exposures in cohorts of workers and by varying age at first exposure within the working age range. What this current study provides is the first direct comparison of the effects of age at first exposure outside of working age, and at cumulative exposures lower than those observed from occupational exposure. The direct evidence provided in this current study is contrary to the prevailing wisdom as summarised in the Committee on Carcinogenicity review. ${ }^{6}$ We have consistently found that mesothelioma rates are lower in those first exposed as children than in those first exposed as adults. However, the amount and type of asbestos exposure that occurred at Wittenoom is markedly different from those that might be able to be accrued from environmental exposures (such as in schools in England). The outdoor environment at Wittenoom was very dusty as a result of the distribution of mill tailings around the town and in the yards of houses. ${ }^{31}$ In addition, Wittenoom children were exposed to crocidolite, the most carcinogenic form of asbestos. ${ }^{32}$

An important strength of this study is that there are more than 60 years of follow-up that ensures that this is one of the only cohorts in the world that can compare the long-term risks of non-occupational asbestos exposure in adults and children. Calendar period-based quantitative asbestos exposure measurements enabled relevant estimates of exposure-response relationships. A limitation of the exposure measurements is that they are based on period and duration of residence at Wittenoom, rather than being based on personal monitors. However, this is unlikely to have impacted on the results as the exposure measurements were derived the same way for the adults and children, so that any errors are likely to be non-differential. A further limitation of this study is that we do not have consistent information on any asbestos exposure after Wittenoom. However, most post-Wittenoom exposure is likely to be orders of magnitude lower than exposure at Wittenoom. From our asbestos job-exposure matrix we estimate that the average annual exposure between 1943 and 1986 for jobs in Australia ranged from $0.0001 \mathrm{f} / \mathrm{mL}$ among carpenters to $2.44 \mathrm{f} / \mathrm{mL}$ for asbestos removalists to $12 \mathrm{f} /$ $\mathrm{mL}$ among those who worked in asbestos cement manufacturing. Most occupations were at the lower end of the exposure 
range. For most, any post-Wittenoom exposure was likely to be mixed fibres (mostly chrysotile), or to asbestos cement with $10 \%-15 \%$ asbestos, mostly chrysotile. ${ }^{33}$ One possible explanation for the higher relative rates in the older exposed group is that they have less opportunity for migration, or other reasons to be lost to follow-up, or being missed during record linkage; however, the similar relative rate when censoring at the date last known to be alive suggests this is unlikely.

In conclusion, children exposed to crocidolite at Wittenoom do not appear to be more vulnerable to mesothelioma, based on their duration of exposure or intensity of exposure. Indeed they appear to have a lower risk, perhaps uniquely for any environmental pollutants. ${ }^{34}$ However, given the long latency and the greater years of life yet to be lived by those exposed as children, it is highly likely that there will be more cases of mesothelioma in the future among those first exposed as children than those first exposed as adults.

Contributors AR undertook the data analysis in conjunction with NHK and NSB All authors contributed to data interpretation. AR drafted the manuscript and all authors contributed to its development.

Funding The authors have not declared a specific grant for this research from any funding agency in the public, commercial or not-for-profit sectors.

Competing interests None declared.

Patient consent Not required.

Ethics approval Human Research Ethics Committee of the University of Western Australia.

Provenance and peer review Not commissioned; externally peer reviewed.

Data sharing statement Applications for access to the data can be made to AR.

\section{REFERENCES}

1 Musk AW, Olsen $\mathrm{N}$, Alfonso $\mathrm{H}$, et al. Predicting survival in malignant mesothelioma. Eur Respir J 2011;38:1420-4

2 Bianchi C, Giarelli L, Grandi G, et al. Latency periods in asbestos-related mesothelioma of the pleura. Eur J Cancer Prev 1997;6:162-6.

3 Reid A, de Klerk NH, Magnani C, et al. Mesothelioma risk after 40 years since first exposure to asbestos: a pooled analysis. Thorax 2014;69:843-50.

4 Gray C, Carey RN, Reid A. Current and future risks of asbestos exposure in the Australian community. Int J Occup Environ Health 2016;22:292-9.

5. United Kingdom Department for Education. The management of asbestos in schools: a review of Department for Education policy. London, 2015.

6 Committee on carcinogenicity of chemicals in food consumer products and the environment. Statement on the relative vulnerability of children to asbestos compared to adults. 2013;29.

7 Reid A, Berry G, de Klerk N, et al. Age and sex differences in malignant mesothelioma after residential exposure to blue asbestos (crocidolite). Chest 2007;131:376-82.

8 Reid A, Franklin P, Olsen N, et al. All-cause mortality and cancer incidence among adults exposed to blue asbestos during childhood. Am J Ind Med 2013;56:133-45.

9 Armstrong BK, de Klerk NH, Musk AW, et al. Mortality in miners and millers of crocidolite in Western Australia. Br J Ind Med 1988;45:5-13.

10 Hansen J, de Klerk NH, Eccles JL, et al. Malignant mesothelioma after environmental exposure to blue asbestos. Int I Cancer 1993;54:578-81.
11 Hansen J, de Klerk NH, Musk AW, et al. Individual exposure levels in people environmentally exposed to crocidolite. Appl Occup Environ Hyg 1997;12:485-90.

12 Hansen J, de Klerk NH, Musk AW, et al. Environmental exposure to crocidolite and mesothelioma: exposure-response relationships. Am J Respir Crit Care Med 1998;157:69-75.

13 de Klerk NH, Musk AW, Ambrosini GL, et al. Vitamin A and cancer prevention II: comparison of the effects of retinol and beta-carotene. Int J Cancer 1998;75:362-7.

14 Musk AW, de Klerk NH, Ambrosini GL, et al. Vitamin A and cancer prevention l: observations in workers previously exposed to asbestos at Wittenoom, Western Australia. Int J Cancer 1998;75:355-61.

15 Reid A, Heyworth J, de Klerk NH, et al. Cancer incidence among women and girls environmentally and occupationally exposed to blue asbestos at Wittenoom, Western Australia. Int J Cancer 2008;122:2337-44.

16 StataCorp. Stata Statistical Software: Release 14 (program). College Station, TX: StataCorp LP, 2015

17 Luce D, Bugel I, Goldberg P, et al. Environmental exposure to tremolite and respiratory cancer in New Caledonia: a case-control study. Am J Epidemiol 2000;151:259-65.

18 Pira E, Pelucchi C, Piolatto PG, et al. First and subsequent asbestos exposures in relation to mesothelioma and lung cancer mortality. Br J Cancer 2007;97:1300-4.

19 Spirtas R, Heineman EF, Bernstein L, et al. Malignant mesothelioma: attributable risk of asbestos exposure. Occup Environ Med 1994;51:804-11.

20 Lacourt A, Leffondré K, Gramond C, et al. Temporal patterns of occupational asbestos exposure and risk of pleural mesothelioma. Eur Respir J 2012;39:1304-12.

21 Rake C, Gilham C, Hatch J, et al. Occupational, domestic and environmental mesothelioma risks in the British population: a case-control study. Br I Cancer 2009:100:1175-83.

22. Chen M, Tse LA, Au RK, et al. Mesothelioma and lung cancer mortality: a historical cohort study among asbestosis workers in Hong Kong. Lung Cancer 2012;76:165-70.

23 Kang D, Myung MS, Kim YK, et al. Systematic review of the effects of asbestos exposure on the risk of cancer between children and adults. Ann Occup Environ Med 2013;25:10

24 Hofmann W, Martonen TB, Graham RC. Predicted Deposition of Nonhygroscopic Aerosols in the Human Lung as a Function of Subject Age. J Aero Med 1989;2:49-68.

25 Berry G, Musk AW, De Klerk NH, et al. Predictions of mortality from mesothelioma. Occup Environ Med 2003;60:458-58.

26 Berry G, Rogers AJ, Pooley FD. Mesotheliomas - asbestos exposure and lung burden. In: Bignon J, Peto J, Saracci R, eds. Non-occupational exposure to mineral fibres. Lyon: IARC Scientific Publications, 1989.

27 Iwatsubo Y, Pairon JC, Boutin C, et al. Pleural mesothelioma: dose-response relation at low levels of asbestos exposure in a French population-based case-control study. Am J Epidemiol 1998;148:133-42.

28 Armstrong B, Driscoll T. Mesothelioma in Australia: cresting the third wave. Public Health Res Pract 2016:26.

29 Burdett G, Cottrell S, Taylor C. Airborne fibre and asbestos concentrations in system built schools. J Phys Conf Ser 2009;151:012023.

30 Burdett GJ, Dewberry K, Staff J. Airborne asbestos exposures from warm air heating systems in schools. Ann Occup Hyg 2016;60:27-39.

31 Layman L. The Blue Asbestos Industry at Wittenoom in Western Australia: a short history. In: Henderson DW SK, Whitaker D, Langlois SLP, eds. Social-Historical, medicolegal, and ethical aspects of Mesothelioma. New York: Hemisphere, 1989:305-27.

32 Hodgson JT, Darnton A. The quantitative risks of mesothelioma and lung cancer in relation to asbestos exposure. Ann Occup Hyg 2000;44:565-601.

33 van Oyen SC, Peters S, Alfonso H, et al. Development of a Job-Exposure Matrix (AsbJEM) to estimate occupational exposure to Asbestos in Australia. Ann Occup Hyg 2015:59:737-48.

34 Suk WA, Ahanchian H, Asante KA, et al. Environmental pollution: an under-recognized threat to children's health, especially in low- and middle-income countries. Environ Health Persp 2016;124:A41-A45. 